\title{
Violência contra crianças na primeira infância: uma análise dos casos notificados no estado do Pará-Brasil no período de 2009 a 2019
}

Violence against children in early childhood: an analysis of the cases notified in the state of ParáBrazil in the period from 2009 to 2019

Violencia contra la niñez en la primera infancia: un análisis de los casos notificados en el estado de Pará-Brasil en el período de 2009 a 2019

Recebido: 09/01/2021 | Revisado: 11/01/2021 | Aceito: 13/01/2021 | Publicado: 17/01/2021

Jocilene Costa Vanzeler

ORCID: https://orcid.org/0000-0002-0853-9540

Universidade Federal do Pará, Brasil

E-mail: joci.costavanzeler@gmail.com

Fernando Augusto Ramos Pontes

ORCID: https://orcid.org/0000-0001-9569-943X Universidade Federal do Pará, Brasil E-mail: farp1304@gmail.com Milene Maria Xavier Veloso

ORCID: https://orcid.org/0000-0002-1035-8968 Universidade Federal do Pará, Brasil E-mail: mileneveloso@hotmail.com

Edson Marcos Leal Soares Ramos ORCID: https://orcid.org/0000-0001-5425-8531 Universidade Federal do Pará, Brasil E-mail: ramosedson@gmail.com

\begin{abstract}
Resumo
O presente estudo teve como objetivo analisar as características da violência praticada contra crianças na fase da primeira infância, notificada pelo setor de saúde no período de janeiro de 2009 a julho de 2019 no estado do ParáBrasil, a partir de uma pesquisa de abordagem quantitativa, descritiva e exploratória. Os resultados demonstraram que a vitimização do sexo feminino $(69,05 \%)$ foi mais notificada que a do sexo masculino $(30,95 \%)$. Em relação à raça/cor, crianças pretas e pardas foram mais vitimadas $(85,20 \%)$, tanto em relação às vítimas do sexo masculino quanto do sexo feminino. A violência ocorreu predominantemente na residência das crianças $(86,26 \%)$. O tipo de violência que se destacou foi a violência sexual (36,35\%), seguido da violência psicológica-sexual $(14,85 \%)$ e da violência física-psicológica-sexual (14,19\%). O conhecido da vítima representou o principal agressor $(52,38 \%)$, seguido do pai em relação às crianças do sexo feminino e da mãe em relação às crianças do sexo masculino. $\mathrm{O}$ autor da violência foi predominantemente do sexo masculino em relação às vítimas do sexo feminino $(56,23 \%)$ e predominante também em relação às vítimas do sexo masculino $(21,47 \%)$. Foi possível verificar a prevalência da violência sexual associado à vítima do sexo feminino e o autor do sexo masculino. Os dados sugerem que um percentual importante de crianças na primeira infância no estado do Pará, estão vulneráveis à violência sexual, o que pode acarretar prejuízos ao seu desenvolvimento ao longo de todo o ciclo de vida.
\end{abstract}

Palavras-chave: Abuso; Infância; Notificação.

\begin{abstract}
The present study aimed to analyze the characteristics of violence practiced against children in early childhood, notified by the health sector from January 2009 to July 2019 in the state of Pará-Brazil, based on a quantitative research, descriptive and exploratory. The results showed that female victimization $(69.05 \%)$ was more reported than male $(30.95 \%)$. Regarding race / color, black and brown children were more victimized (85.20\%), both in relation to male and female victims. Violence occurred predominantly in the children's homes $(86.26 \%)$. The type of violence that stood out was sexual violence $(36.35 \%)$, followed by psychological-sexual violence (14.85\%) and physicalpsychological-sexual violence (14.19\%). The victim's acquaintance represented the main aggressor (52.38\%), followed by the father in relation to female children and the mother in relation to male children. The perpetrator of violence was predominantly male in relation to female victims $(56.23 \%)$ and also predominant in relation to male victims $(21.47 \%)$. It was possible to verify the prevalence of sexual violence associated with the female victim and the male author. The data suggest that an important percentage of children in early childhood in the state of Pará, are vulnerable to sexual violence, which can damage their development throughout the life cycle.
\end{abstract}

Keywords: Abuse; Childhood; Notification. 


\begin{abstract}
Resumen
El presente estudio tuvo como objetivo analizar las características de la violencia practicada contra los niños en la primera infancia, notificada por el sector salud de enero de 2009 a julio de 2019 en el estado de Pará-Brasil, a partir de una investigación cuantitativa. , descriptivo y exploratorio. Los resultados mostraron que la victimización femenina $(69,05 \%)$ fue más denunciada que la masculina (30,95\%). En cuanto a raza / color, los niños negros y morenos fueron más victimizados $(85,20 \%)$, tanto en relación a las víctimas masculinas como femeninas. La violencia ocurrió predominantemente en los hogares de los niños $(86,26 \%)$. El tipo de violencia que se destacó fue la violencia sexual $(36,35 \%)$, seguida de la violencia psicológica-sexual (14,85\%) y la violencia física-psicológica-sexual $(14,19 \%)$. El conocido de la víctima representó el principal agresor (52,38\%), seguido por el padre en relación a las hijas y la madre en relación a los hijos varones. El autor de la violencia fue predominantemente masculino en relación con las mujeres víctimas $(56,23 \%)$ y también predominante en relación con los hombres víctimas $(21,47 \%)$. Se pudo verificar la prevalencia de violencia sexual asociada a la mujer víctima y al autor masculino. Los datos sugieren que un porcentaje importante de niños en la primera infancia en el estado de Pará, son vulnerables a la violencia sexual, lo que puede dañar su desarrollo durante todo el ciclo de vida.
\end{abstract}

Palabras clave: Abuso; Infancia; Notificación.

\title{
1. Introdução
}

A primeira infância é a etapa do desenvolvimento humano que compreende ao período que abrange os primeiros 6 (seis) anos de vida completos ou 72 (setenta e dois) meses de vida da criança (Brasil, 2016). Nesta fase acontecem importantes maturações físicas e neurológicas, aprendizados sociais e afetivos na criança. E por se encontrarem em processo de crescimento e desenvolvimento, as crianças também apresentam maior vulnerabilidade no que concerne à violência, o que pode repercutir em um aumento na chance de ocorrência de problemas posteriores, tanto físicos quanto psíquicos podendo incluir doenças transmissíveis e não transmissíveis, danos psicológicos, comportamentos de risco, deficiência de desempenho educacional ou ocupacional e envolvimento em crimes (Walker et al., 2011; Sanchez et al., 2006; NCPI, 2014).

Com isso, a exposição à violência na infância pode prejudicar o desenvolvimento cerebral da criança e produzir danos em outras partes do sistema nervoso, bem como nos sistemas endócrino, circulatório, músculo-esquelético, reprodutivo, respiratório e imune, com consequências ao longo de toda a vida (Felitti et al., 2019).

Todavia, as consequências da violência atingem de forma imediata a criança, ocasionando danos físicos e psicológicos, e vão além da esfera individual da criança, pois afeta em longo prazo a saúde pública e os custos econômicos comprometendo os investimentos em educação, saúde e bem-estar da criança, e reduzindo a capacidade produtiva desses sujeitos ao atingirem a idade adulta (WHO, 2016).

De acordo com a Organização Mundial de Saúde (OMS) a violência é definida como o uso intencional da força ou do poder, real ou em ameaça, contra si próprio, contra outra pessoa, ou contra um grupo ou uma comunidade, que resulte ou tenha possibilidade de resultar em lesão, morte, dano psicológico, deficiência de desenvolvimento ou privação. Sendo assim, é considerada um dos mais graves problemas sociais e de saúde pública, apresentando, junto aos acidentes, grande influência nas questões de adoecimento e morte precoce da população, com efeitos na expectativa e qualidade de vida de crianças, adolescentes e adultos em geral (WHO, 2002).

A violência ocorrida especificamente contra crianças é caracterizada como todo ato ou omissão que possa causar dano físico, sexual e/ou psicológico, em que a proteção desta é negligenciada, seja pelos pais, seja pelos parentes, pelas instituições e pela sociedade em geral (Minayo, 2001).

Trata-se de uma violência as vezes sutil, em geral invisível, cuja gravidade pode escapar ao juízo da sociedade na qual se encontra naturalizada, visto que ao longo de muitos anos perdurou e ainda persiste a ideia de que utilizar castigos, intimidar com o olhar, mandar calar, entre outros comportamentos dos adultos, pais ou responsáveis, seriam meios adequados para educar e ou disciplinar uma criança (Sekkel, 2009).

A OMS também estabelece distinções sobre as naturezas da violência contra crianças, sendo elas: violência física; violência psicológica/moral; tortura; violência sexual; tráfico de seres humanos; violência financeira/econômica; 
negligência/abandono; trabalho infantil; intervenção legal. Diante dos diversos tipos de violência, é importante definir as formas analisadas na pesquisa: violência física, violência psicológica e violência sexual.

A violência física é caracterizada como todo ato violento com uso da força física de forma intencional, não acidental, praticada por pais, responsáveis, familiares ou pessoas próximas da criança ou adolescente, que pode ferir, lesar, provocar dor e sofrimento ou destruir a pessoa, deixando ou não marcas evidentes no corpo, e podendo provocar inclusive a morte. As atitudes que identificam esse tipo de violência variam entre tapas, beliscões, chutes e arremessos de objetos, o que causa lesões, traumas, queimaduras e mutilações (Brasil, 2010). É uma das formas mais frequentes de violência que ocorre dentro do ambiente familiar, apesar de subnotifica, pois está estritamente ligada a costumes que foram introduzidos no Brasil desde os jesuítas, que puniam com palmadas e no tronco quem ousasse se manifestar na escola jesuítica (Porto, 2006).

A violência psicológica é toda ação que coloca em risco ou causa dano à autoestima, à identidade ou ao desenvolvimento de uma criança. São atitudes que se manifestam em forma de rejeição, depreciação, discriminação, desrespeito, cobrança exagerada, punições humilhantes e utilização da criança ou do adolescente para atender às necessidades psíquicas de outrem (Brasil, 2010). É também denominada de tortura psicológica, ocorre quando adultos sistematicamente depreciam crianças, bloqueiam seus esforços de autoestima e realização, ou as ameaçam de abandono e crueldade. Trata-se de um tipo de relação ainda pouco estudada, mas que tem um efeito perverso no desenvolvimento infanto-juvenil (Minayo, 2001).

A violência sexual é todo ato, de qualquer natureza, atentatório ao desenvolvimento sexual da criança e do adolescente, praticado por agente em situação de poder e de desenvolvimento sexual desigual, segundo definição estabelecida pelo plano nacional de enfrentamento a violência sexual contra crianças e adolescentes (Brasil, 2013). Pode também ser caracterizada como todo ato ou jogo sexual com intenção de estimular sexualmente a criança ou o adolescente para obter satisfação sexual, estando os autores da violência em estágio de desenvolvimento psicossexual mais adiantado que a criança ou adolescente. Abrange uma variedade de comportamentos e atitudes caracterizadas como crime, tais quais: estupro, incesto, assédio sexual, exploração sexual, pornografia, pedofilia, manipulação de genitália, mamas e ânus, até o ato sexual com penetração, imposição de intimidades, exibicionismo, jogos sexuais e práticas eróticas não consentidas e impostas e "voyeurismo" (obtenção de prazer sexual por meio da observação), dentre outras (Brasil, 2010).

Diante disso, o conhecimento das peculiaridades do desenvolvimento das crianças principalmente na fase da primeira infância requer um processo de conscientização e identificação mais rigoroso e proativo, porque essas crianças são fisicamente dependentes dos adultos e estão em situação peculiar de desenvolvimento. Portanto, abordar o abuso infantil nos primeiros anos de vida oferece uma excelente oportunidade para auxiliar as vítimas mais vulneráveis e reduzir efetivamente o impacto nas famílias e comunidades nos anos seguintes (Fredrickson, 2019).

Além disso, é importante destacar que as inúmeras dificuldades no enfrentamento da violência encontram-se no próprio reconhecimento da existência da violência, ou outras vezes ela é visibilizada, mas a vítima é culpabilizada por ter "provocado" tal violência. Estudos mostram que há uma naturalização da violência em geral e em específico da infantil, dadas as formas de interpretação da infância que predominaram por muito tempo na história das civilizações (Egry et al., 2017).

O aumento no número de casos de violência infantil, segundo os dados epidemiológicos mundiais e nacionais, mostra que é cada vez mais necessário demandar ações de controle, por meio de condutas preventivas, pelos setores sociais envolvidos, bem como profissionais de saúde, conselhos tutelares, entre outros (Nunes e Sales, 2016).

De acordo com o Boletim Epidemiológico da Secretaria de Vigilância em Saúde do Ministério da Saúde publicado em julho de 2020, o número de notificações de violência contra criança no Brasil mais do que triplicou, passou de 13.249 para 45.967 casos, no período de 2011 a 2018 (Brasil, 2020a).

Segundo dados do Disque 100 (Disque Direitos Humanos), divulgado em junho de 2019 pelo Ministério da Mulher, da Família e dos Direitos Humanos do governo federal, foram registrados 152.178 tipos de violações contra crianças e 
adolescentes em 2018 no Brasil. Os tipos de violação mais frequentes foram: negligência (72,7\%), seguida por violência psicológica $(48,8 \%)$, física $(40,6 \%)$ e sexual $(22,4 \%)$. Entre as vítimas, $48,16 \%$ são do sexo feminino, $40,24 \%$ masculino e 11,60\% não informados. Sobre a faixa etária, 0 a 3 anos (17,84\%), 4 a 7 anos (21,48\%), 8 a 11 anos (20,10\%), 12 a 14 anos $(17,44 \%), 15$ a 17 anos $(11,93 \%)$, nascituro $(0,24 \%)$, recém-nascido $(0,83 \%)$, não informado $(11,93 \%)$. No que tange à relação entre suspeito e vítima, as mães são as principais denunciadas no que se refere às violações - elas representam 37,64\%, em seguida os pais $(18,47 \%)$, padrastos $(5,32 \%)$, tios/as $(3,53 \%)$ e as avós $(3,59 \%)$. Tendo um percentual de $18,77 \%$ de não informados (Brasil, 2019a).

Em geral, os autores são aqueles que deveriam protegê-los ou que têm relação de proximidade com as vítimas: pais, mães, padrastos e outros membros da família. Contudo, segundo dados do Boletim Epidemiológico da Secretaria de Vigilância em Saúde do Ministério da Saúde de julho de 2020, mais de 60\% das denúncias de violação de direitos ocorrem na própria casa e na escola, espaços que deveriam ser locais de proteção (Brasil, 2020a).

Destarte, as ações brasileiras têm avançado no que se refere ao investimento na primeira infância, como a inclusão do atendimento prioritário estabelecido no Plano Plurianual (PPA) da União para o quadriênio de 2020 a 2023. O parágrafo único do art. 10 do PPA 2020-2023 prevê um conjunto de ações governamentais voltadas ao atendimento da primeira infância com caráter prioritário para o orçamento de 2020, nos termos do art. $3^{\circ}$ da Lei ${ }^{\circ} 13.971$, de 27 de dezembro de 2019, e possui antecedência na programação e na execução orçamentária e financeira durante o quadriênio respectivo (Brasil, 2019b).

Além disso, a partir das informações registradas nos sistemas de notificação, vem sendo possível dimensionar a magnitude da violência no país, planejar o investimento em núcleos de vigilância e assistência, possibilitar a garantia dos direitos de crianças e adolescentes e subsidiar pesquisas e ajustes na rede de proteção (Assis et al., 2012).

Dentre os avanços na legislação brasileira, a Constituição Federal de 1988 representou um marco para os direitos das crianças no Brasil ao reconhecê-las como sujeitos de direitos e assegurando em seu artigo 227 o direito à inviolabilidade da integridade física, psíquica e moral, abrangendo a identidade, a autonomia, os valores, as ideias e o direito de opinião de toda criança e adolescente, de forma a promover seu desenvolvimento pleno (Brasil, 1998).

Em seguida, foi aprovado o Estatuto da Criança e do Adolescente (ECA), em 1990, o qual representa da mesma forma um avanço significativo para a consolidação dos direitos desses sujeitos. O ECA prevê que tanto o governo brasileiro quanto a sociedade em geral devem proteger crianças e adolescentes de toda e qualquer forma de violência e determina penalidades em caso de violações de tais direitos (Brasil, 1990).

Ressalta-se, também, que o ECA estabeleceu a obrigatoriedade da notificação de qualquer tipo de violência contra crianças e adolescentes e definiu a punição para os profissionais que são omissos a qualquer tipo de violação de direitos a esses sujeitos, conforme disposto no art. 245 do referido estatuto.

De acordo com o Atlas da Violência 2020, o ECA reduziu a escalada da violência contra crianças no Brasil, sendo que antes da criação do Estatuto, no período de 1980 a 1991, a violência contra crianças de 0 a 9 anos de idade correspondeu a $2,8 \%$ dos casos, sendo que este percentual reduziu pouco mais da metade nos anos de 1991 a 2018, com um percentual de $1,2 \%$ (Brasil, 2020b).

Na legislação brasileira, é importante também citar a criação da Lei de Diretrizes e Bases da Educação (LDB), em 1996, que define a educação infantil como a primeira etapa da educação básica, oferecida em centros de educação infantil e creches públicas. Cabe destacar que em 2009, a Emenda Constitucional n ${ }^{\circ} 59$ estabeleceu como obrigação, e não apenas como direito, o acesso à educação infantil para meninos e meninas a partir dos 4 anos de idade. A LDB também determina no inciso IX do artigo 12 que os estabelecimentos de ensino, respeitadas as normas comuns e as do seu sistema de ensino, terão a incumbência de promover medidas de conscientização, de prevenção e de combate a todos os tipos de violência, especialmente a intimidação sistemática (bullying), no âmbito das escolas. Além disso, prevê no $\S 9^{\circ}$ do art. 26 a inclusão como temas 
transversais nos currículos escolares os conteúdos relativos aos direitos humanos e à prevenção de todas as formas de violência contra a criança e o adolescente (Brasil, 1996).

Importante também destacar a criação da Lei nº 13.010/2014 (Lei Menino Bernardo), que também altera dispositivo do ECA, bem como da LDB, para estabelecer o direito da criança e do adolescente de serem educados e cuidados sem o uso de castigos físicos ou de tratamento cruel ou degradante. A referida Lei define e proíbe o uso de castigos físicos e tratamento cruel ou degradante com o pretexto de educar em lares, escolas e outros espaços de convivência de crianças e adolescentes (Brasil, 2014).

No que se refere a legislação específica da primeira infância, foi sancionada em 8 de março de 2016, a Lei nº 13.257 , referente ao Marco Legal da primeira infância, que dispõe sobre a formulação e implementação de políticas públicas para a faixa etária de zero a seis anos de idade. O Marco Legal visa superar a segmentação de ações, aumentando a eficácia das políticas voltadas para a infância e definindo estratégias de articulação intersetorial. O Art. $5^{\circ}$ da Lei no 13.257/2016 dispõe sobre as áreas prioritárias para as políticas públicas para a primeira infância: a saúde, a alimentação e a nutrição, a educação infantil, a convivência familiar e comunitária, a assistência social à família da criança, a cultura, o brincar e o lazer, o espaço e o meio ambiente, bem como a proteção contra toda forma de violência e de pressão consumista, a prevenção de acidentes e a adoção de medidas que evitem a exposição precoce à comunicação mercadológica. Além disso, a lei do Marco Legal da Primeira Infância alterou o art. 88 do ECA para incluir o inciso X onde prevê que são diretrizes da política de atendimento a realização e divulgação de pesquisas sobre desenvolvimento infantil e sobre prevenção da violência (Brasil, 2016).

Importante ainda destacar a criação da lei no 13.960 de 19 de dezembro de 2019, que instituiu o Biênio da Primeira Infância do Brasil no período de 2020-2021. Esta lei visa principalmente, entre outras ações, permitir iniciativas e ações do poder público em parceria com entidades médicas, universidades, associações e sociedade civil, na organização de palestras, eventos e treinamentos, com o objetivo de informar a sociedade da importância de promover o desenvolvimento infantil nos primeiros anos de vida da criança (Brasil, 2019c).

No Pará, em especial na capital Belém, o sistema de notificação de casos de violência foi implantado em 2009 e fez parte de um inquérito nacional a fim de caracterizar as vítimas de violência e acidentes atendidos em serviços de urgência em todas as capitais do Brasil. A partir de então, foram realizadas capacitações dos profissionais de saúde para o uso da ficha de notificação de violência doméstica, sexual e outras violências, bem como para o conhecimento do fluxo dessas violências na rede, até o registro no Sistema Nacional de Registros de Notificação - SINAN (Veloso et al., 2013).

Apesar dos avanços mencionados em torno da questão das políticas de proteção e prevenção à violência contra crianças e adolescentes, o cenário brasileiro ainda é desfavorável e as violências ainda estão presentes no cotidiano de muitas crianças e adolescentes. Diante disso, o presente estudo objetivou analisar as características da violência praticada contra crianças, na primeira infância, a fim de permitir a visibilidade e o dimensionamento deste fenômeno e contribuir para a conscientização sobre o problema, bem como para a proposição de políticas públicas específicas nesta fase do desenvolvimento humano.

\section{Metodologia}

Trata-se de uma pesquisa do tipo documental, de abordagem descritiva e exploratória, e de natureza quantitativa. Nos métodos quantitativos, faz-se a coleta de dados quantitativos ou numéricos por meio do uso de medições de grandezas que podem ser analisados por meio de técnicas matemáticas como porcentagens, estatísticas e probabilidades, métodos numéricos, métodos analíticos e geração de equações e/ou fórmulas matemáticas aplicáveis a algum processo (Pereira et al., 2018).

Foram analisadas as ocorrências dos casos de violência contra crianças na faixa etária de zero a seis anos notificados 
no estado do Pará-Brasil e registrados no banco de dados do Sistema de Notificação de Agravos de Notificação (SINAN), no período de 2009 a 2019.

Os dados foram coletados pelo projeto de pesquisa intitulado "Violência contra crianças e adolescentes: indicadores e estratégias de enfrentamento" desenvolvido na Faculdade de Psicologia da Universidade Federal do Pará e disponibilizados à coordenadora do referido projeto pelo Departamento de Vigilância Epidemiológica da Secretaria de Saúde Pública do estado do Pará-Brasil.

A faixa etária de zero a seis anos de idade, foi estabelecida de acordo com o critério de idade definido no Marco Legal da Primeira Infância. O recorte temporal foi definido com a finalidade de demonstrar os dados registrados no período de 10 anos, considerando o período de janeiro de 2009 a julho de 2019.

O instrumento utilizado para notificar os casos de violência é a ficha de notificação disponibilizada pelo Ministério da Saúde, na qual classifica-se os tipos de violência em violência física, violência psicológica/moral, violência sexual, violência financeira/econômica, negligência/abandono, tortura, tráfico de seres humanos, trabalho infantil, intervenção legal e outros tipos. Contudo, destes tipos foram demonstrados em especial os dados dos casos de violência sexual, psicológica/moral e física porque representam as maiores ocorrências notificadas no período analisado.

O banco de dados é alimentado pelas informações contidas na ficha de notificação individual que está estruturada em dez blocos, quais sejam: Dados gerais, notificação individual, dados de residência, dados da pessoa atendida, dados da ocorrência, violência, violência sexual, dados do provável autor da violência, encaminhamento e dados finais, além de campos destinados para informações complementares e observações.

As variáveis deste estudo foram definidas de acordo com a ficha de notificação e divididas em quatro categorias: 1 . Dados da notificação individual: Sexo, Idade e raça da vítima; 2. Dados da ocorrência: Local do fato; 3. Dados do autor da violência: Sexo e relação com a vítima e 4. Tipos de violência: Sexual, psicológica/moral e física.

Inicialmente, para análise dos dados foram construídas planilhas no formato Microsoft Excel@ 2013 a partir do banco de dados do SINAN para organização das variáveis estudadas na pesquisa. Posteriormente, foi realizada a sistematização dos dados para a realização da pesquisa descritiva e construídas tabelas e gráficos por meio do recurso da tabela dinâmica. Esses processos estatísticos permitem obter representações simples e constatar se essas verificações têm relações entre si (Marconi e Lakatos, 2009).

Com intuito de realizar uma análise mais aprofundada dos dados, foi aplicada a técnica da análise de correspondência que é uma técnica estatística exploratória utilizada para verificar associações ou similaridades entre variáveis qualitativas ou variáveis contínuas categorizadas, tendo como objetivo a representação ótima da estrutura dos dados observados. A principal característica é a redução de dados a serem analisados pelo pesquisador com perda mínima de informações, transformando as linhas e colunas das tabelas em unidades correspondentes, o que facilita a representação conjunta dos dados, onde essa correspondência é fundamental para a construção dos gráficos (Fávero et al., 2009).

A análise de correspondência foi realizada com o auxílio do aplicativo Statistica, versão 6.0. Em todos os testes, fixou-se $\alpha=5 \%(\mathrm{p} \leq 0,05)$ para rejeição da hipótese nula. Para realizar a análise de correspondência, as variáveis relacionadas às crianças de 0 a 6 anos foram categorizadas da seguinte maneira: (i) Sexo: Masculino e Feminino; (ii) Faixa Etária: 0 a 1 ano; 2 a 4 anos e 5 a 6 anos; (iii) Raça/Cor: Preta-Parda; Branca; Amarela e Indígena; (iv) Local do fato: Escola; Habitação Coletiva; Residência e Outros (Ambiente Virtual; Barco; Conselho Tutelar; Creche; Dentro do Carro; Fazenda; Hospital; Igarapé; Igreja; Mata; Motel; Residência da Babá; Residência da Mãe; Residência de um parente (Tio(a), Irmão(ã), Avô(ó); Primo(a)); Residência do Pai; Residência do(a) Vizinho(a); Residência do(a) Amigo(a); Sítio e etc.); (v) Tipo de Violência: Física; Psicológica; Sexual; Outras (Abandono; Patrimonial; Tortura; Trabalho Infantil e etc.) e suas combinações duplas (por exemplo, Física-Psicológica) e triplas (por exemplo, Física-Psicológica-Sexual); (vi) Tipo de Relação com o(a) Autor(a): Mãe; 
Pai; Irmão(ã); Padrasto; Conhecidos(as); Desconhecido(a); Pai e Mãe e Mãe e Padrasto; (vii) Sexo do(a) Autor(a): Masculino; Feminino e Ambos.

\section{Resultados}

No período de 2009 a 2019 foram notificados 5.140 casos de violência contra crianças na idade de zero a seis anos no Pará, conforme dados do SINAN. Dentre estes, 2.341 casos ocorreram no município de Belém (capital do estado do Pará) e 638 casos ocorreram no município de Ananindeua, localizada na região metropolitana de Belém, sendo que juntos representam $51,40 \%$ dos casos ocorridos em todo o estado (Figura 1).

Figura 1: Mapa da quantidade de crianças de 0 a 6 anos, vítimas de violência no estado do Pará, no período de 2009 a 2019 , por município.

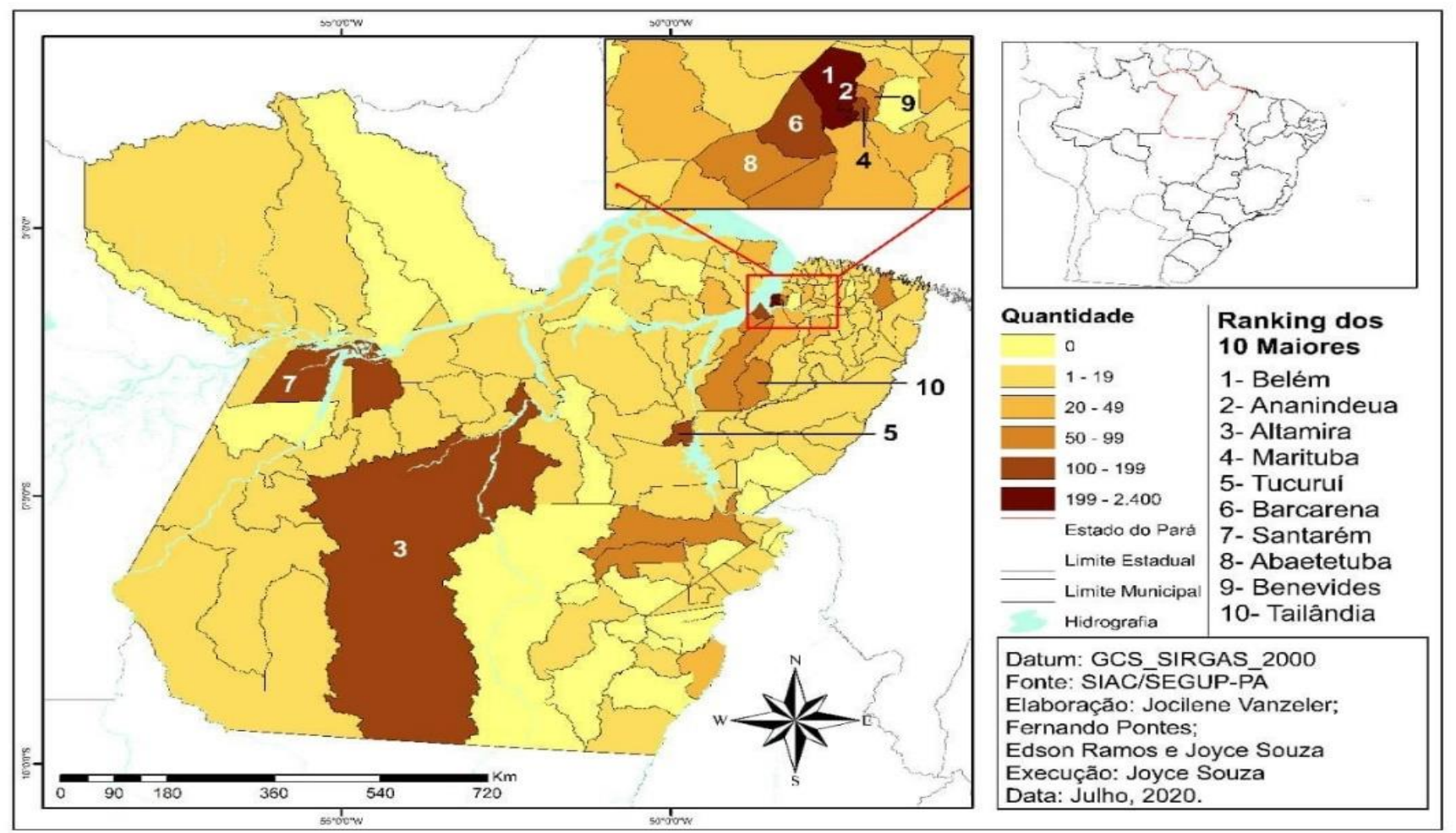

Fonte: Sistema de Informação de Agravos de Notificação (SINAN). Adaptado pelos autores.

As variáveis apresentadas na Tabela 1 foram analisadas por meio de estatística descritiva. Pela análise dos dados registrados, pode-se verificar que 69,05\% dos casos são de vítimas do sexo feminino, sendo 30,95\% de vítimas do sexo masculino, crianças do sexo feminino na idade de 5 anos apresentam um percentual de 12,90\% dos casos e crianças do sexo masculino a idade de 6 anos representa $12,55 \%$ dos casos ocorridos e registrados, a raça preta/parda analisada pela totalidade de casos tanto de meninos quanto de meninas, representa 85,20\% dos casos. Sobre o local do fato, a residência das crianças corresponde a $86,26 \%$ do total dos casos. Em relação ao tipo de violência, a violência sexual representa um percentual de $36,35 \%$ dos casos, a violência psicológica-sexual apresenta 14,85\% e a violência física-psicológica-sexual 14,19\% dos casos. O conhecido da vítima obteve um percentual de 52,38\%, representando o maior agressor de crianças na primeira infância, seguido do pai em relação às vítimas do sexo feminino e da mãe em relação às vítimas do sexo masculino. $\mathrm{O}$ autor da violência que aparece em 56,23\% dos casos de violência contra vítimas do sexo feminino é do sexo masculino, em relação a vítima do sexo masculino, o autor do sexo masculino também é predominante em $21,47 \%$ dos casos. 
Tabela 1: Percentual de crianças de 0 a 6 anos, vítimas de violência no estado do Pará, no período de 2009 a 2019, por sexo; idade; raça/cor; local do fato; tipo de violência; tipo de relação com o(a) autor(a) e sexo do autor(a).

\begin{tabular}{|c|c|c|c|c|}
\hline \multirow[b]{2}{*}{ Variável } & \multirow[b]{2}{*}{ Categoria } & \multicolumn{2}{|c|}{ Sexo da Vítima } & \multirow[t]{2}{*}{ Total $(\%)$} \\
\hline & & $\begin{array}{l}\text { Masculino } \\
(\%)\end{array}$ & Feminino $(\%)$ & \\
\hline \multirow{8}{*}{$\begin{array}{l}\text { Idade da } \\
\text { Criança }\end{array}$} & $<1$ & 3,75 & 7,61 & 11,36 \\
\hline & 1 & 2,68 & 5,41 & 8,09 \\
\hline & 2 & 3,81 & 8,09 & 11,90 \\
\hline & 3 & 4,01 & 11,11 & 15,12 \\
\hline & 4 & 5,10 & 11,38 & 16,48 \\
\hline & 5 & 5,76 & 12,90 & 18,66 \\
\hline & 6 & 5,84 & 12,55 & 18,39 \\
\hline & Total & 30,95 & 69,05 & 100,00 \\
\hline \multirow{5}{*}{ Raça/Cor } & Preta-Parda & 26,84 & 58,36 & 85,20 \\
\hline & Branca & 3,61 & 10,18 & 13,79 \\
\hline & Indígena & 0,09 & 0,57 & 0,66 \\
\hline & Amarela & 0,09 & 0,26 & 0,35 \\
\hline & Total & 30,63 & 69,37 & 100,00 \\
\hline \multirow{5}{*}{$\begin{array}{l}\text { Local do } \\
\text { Fato }\end{array}$} & Residência & 25,69 & 60,57 & 86,26 \\
\hline & Escola & 1,11 & 1,63 & 2,74 \\
\hline & Habitação Coletiva & 0,20 & 0,31 & 0,51 \\
\hline & Outros* & 4,55 & 5,95 & 10,50 \\
\hline & Total & 31,55 & 68,46 & 100,01 \\
\hline \multirow{15}{*}{$\begin{array}{l}\text { Tipo de } \\
\text { Violência }\end{array}$} & Física & 5,03 & 4,65 & 9,68 \\
\hline & Psicológica & 0,44 & 0,89 & 1,33 \\
\hline & Sexual & 7,94 & 28,41 & 36,35 \\
\hline & Outras $* *$ & 4,99 & 5,29 & 10,28 \\
\hline & Física-Psicológica & 1,94 & 2,50 & 4,44 \\
\hline & Física-Sexual & 0,71 & 2,24 & 2,95 \\
\hline & Física-Outras** & 1,78 & 1,45 & 3,23 \\
\hline & Psicológica-Sexual & 3,86 & 10,99 & 14,85 \\
\hline & Psicológica-Outras** & 0,22 & 0,40 & 0,62 \\
\hline & Física-Psicológica-Sexual & 3,53 & 10,66 & 14,19 \\
\hline & $\begin{array}{l}\text { Física-Psicológica- } \\
\text { Outras** }\end{array}$ & 0,65 & 0,81 & 1,46 \\
\hline & Física-Sexual-Outras** & 0,04 & 0,18 & 0,22 \\
\hline & Psicológica-Sexual- & & & \\
\hline & Outras** & 0,08 & 0,32 & 0,40 \\
\hline & Total & 31,21 & 68,79 & 100,00 \\
\hline \multirow{9}{*}{$\begin{array}{l}\text { Tipo de } \\
\text { Relação }\end{array}$} & Mãe & 4,91 & 4,99 & 9,90 \\
\hline & Pai & 3,46 & 9,43 & 12,89 \\
\hline & Irmão(ã) & 0,58 & 1,29 & 1,87 \\
\hline & Padrasto & 1,78 & 7,67 & 9,45 \\
\hline & Conhecidos(as) & 16,45 & 35,93 & 52,38 \\
\hline & Desconhecido(a) & 2,32 & 6,22 & 8,54 \\
\hline & Pai e Mãe & 1,87 & 2,27 & 4,14 \\
\hline & Mãe e Padrasto & 0,29 & 0,54 & 0,83 \\
\hline & Total & 31,66 & 68,34 & 100,00 \\
\hline \multirow{4}{*}{$\begin{array}{l}\text { Sexo do } \\
\text { Autor }\end{array}$} & Masculino & 21,47 & 56,23 & 77,70 \\
\hline & Feminino & 6,99 & 8,84 & 15,83 \\
\hline & Ambos & 2,75 & 3,72 & 6,47 \\
\hline & Total & 31,21 & 68,79 & 100,00 \\
\hline
\end{tabular}

.*Outros: (Ambiente virtual; Barco; Conselho tutelar; Creche; Dentro do carro; Fazenda; Hospital; Igarapé; Igreja; Mata; Motel; Residência da babá; Residência da mãe; Residência de um parente (Tio(a), Irmão(ã), Avô(ó); Primo(a)); Residência do pai; Residência do(a) vizinho(a); Residência do(a) amigo(a); Sítio e etc.).

**Outras: (Abandono; Patrimonial; Tortura; Trabalho Infantil e etc.).

Fonte: Sistema de Informação de Agravos de Notificação (SINAN). Adaptado pelos autores 
Pela aplicação da análise de correspondência, importante observar que os valores do nível descritivo (p) menores que o nível de significância de 0,05 (5\%) e do Critério Beta ( $\beta$ ) maior ou igual que 3, indicam que tanto as variáveis como suas categorias são dependentes (Tabela 2). Além disso, pode-se observar que a soma dos percentuais de inércia indica que mais que 70\% da informação foi restituída pela AC. Desta forma todos os pressupostos para utilização da técnica de Análise de Correspondência são satisfeitos.

Tabela 2: Estatísticas resultantes da aplicação da técnica de análise de correspondência às variáveis: Sexo da criança de 0 a 6 anos vítima; Raça/cor; Local do fato; Tipo de violência; Tipo de relação com o(a) autor(a) e Sexo do autor(a).

\begin{tabular}{lrrrc}
\hline Variáveis & \multicolumn{1}{c}{$\boldsymbol{\chi}^{\mathbf{2}}$} & \multicolumn{1}{c}{$\boldsymbol{B}$} & \% Inércia & $\boldsymbol{p}$ \\
\hline Sexo da Vítima versus Raça & 11,77 & 5,06 & 100,00 & 0,008 \\
Sexo da Vítima versus Local do Fato & 42,14 & 22,60 & 100,00 & 0,000 \\
Sexo da Vítima versus Tipo de Violência & 333,16 & 92,71 & 100,00 & 0,000 \\
Sexo da Vítima versus Relação com Autor(a) & 123,56 & 44,06 & 100,00 & 0,000 \\
Sexo da Vítima versus Sexo do Autor(a) & 92,52 & 64,01 & 100,00 & 0,000 \\
\hline
\end{tabular}

$\chi 2$ : Valor do Qui-quadrado; $\beta$ : Valor do critério Beta; $\mathrm{p}$ : Nível descritivo.

Fonte: Sistema de informação de agravos de notificação (SINAN). Adaptado pelos autores.

Na Tabela 3, pode-se observar que crianças vítimas do sexo masculino estão associadas à raça/cor preta-parda e crianças vítimas do sexo feminino estão associadas às raças/cor branca e indígena. A vitimização comedida em crianças da raça amarela apresentou resíduos no intervalo $(-0,41$ a 0,41$)$, isto é, dentro do intervalo $(-0,67$ a 0,67$)$, nas duas categorias da variável sexo da vítima, o que significa que estatisticamente crianças da raça amarela de ambos os sexos (masculino e feminino) são vitimadas igualmente. Crianças do sexo masculino estão associadas a vitimização em escolas e a outros locais, já crianças do sexo feminino estão associadas a vitimização em residência. A vitimização comedida em crianças em habitação coletiva apresentou resíduos no intervalo $(-0,65$ a 0,65$)$, isto é, dentro do intervalo $(-0,67$ a 0,67$)$, nas duas categorias da variável sexo da vítima, o que significa que estatisticamente crianças de ambos os sexos (masculino e feminino) são vitimadas em habitação coletiva. Crianças do sexo masculino estão associadas às violências do tipo física e outros tipos de violência e, também, as combinações das violências física-psicológica; física-outras e física-psicológica-outras, enquanto que crianças do sexo feminino estão associadas à violência do tipo sexual e, também, as combinações das violências física-sexual; psicológicasexual e física-psicológica-sexual. A violência psicológica e a combinações psicológica-outras apresentaram resíduos nos intervalos: (i) psicológica $(-0,41$ a 0,41$)$ e (ii) psicológica-outras $(-0,43$ a 0,43$)$, isto é, dentro do intervalo $(-0,67$ a 0,67$)$, nas duas categorias da variável sexo da vítima, o que significa que estatisticamente crianças de ambos os sexos (masculino e feminino) são vítimas de violência psicológica e da combinação violência psicológica-outras. As combinações física-sexualoutras e psicologia-sexual-outras não apresentaram associação estatisticamente significativa em relação a vitimização de crianças de ambos os sexos. Crianças do sexo masculino estão associadas à vitimização cometida pela mãe e pai e mãe, já crianças do sexo feminino estão associadas à vitimização cometida pelo pai, pelo padrasto e por desconhecido. A vitimização comedida por irmão(a); conhecido(a), mãe-padrasto apresentou, respectivamente, resíduos nos intervalos: (i) irmão (0,12 a 0,12); (ii) conhecidos $(0,21$ a -0,21) e (iii) mãe-padrasto $(0,38$ a -0,38), isto é, dentro do intervalo $(-0,67$ a 0,67$)$, nas duas categorias da variável sexo da vítima, o que significa que crianças de ambos os sexos (masculino e feminino) são vitimadas por irmão(ãs), pessoas conhecidas e mãe-padrasto. Crianças do sexo masculino estão associadas à vitimização cometida por autores do sexo feminino e de ambos os sexos, já crianças do sexo feminino estão associadas à vitimização cometida por autores do sexo masculino. 
Tabela 3: Resíduos e níveis de confiança (entre parênteses), Resultantes da aplicação da técnica de análise de correspondência às variáveis: Sexo da criança; Raça/cor; Local do fato; Tipo de violência; Tipo de relação com o(a) autor(a) e Sexo do autor(a).

\begin{tabular}{|c|c|c|c|}
\hline \multirow{2}{*}{ Variável } & \multirow{2}{*}{ Categoria } & \multicolumn{2}{|c|}{ Sexo } \\
\hline & & Masculino & Feminino \\
\hline \multirow{4}{*}{ Raça/Cor } & Preta-Parda & $0,99(67,76)^{* *}$ & $-0,66(0,00)$ \\
\hline & Branca & $-2,02(0,00)$ & $1,34(82,10)^{*}$ \\
\hline & Amarela & $-0,41(0,00)$ & $0,27(21,31)$ \\
\hline & Indígena & $-1,71(0,00)$ & $1,14(74,46)^{*}$ \\
\hline \multirow{4}{*}{ Local do Fato } & Escola & $1,78(92,57)^{*}$ & $-1,21(0,00)$ \\
\hline & Habitação Coletiva & $0,65(48,27)$ & $-0,44(0,00)$ \\
\hline & Residência & $-1,98(0,00)$ & $1,34(82,09)^{*}$ \\
\hline & Outros $^{1}$ & $4,62(100,00)^{*}$ & $-3,13(0,00)$ \\
\hline \multirow{13}{*}{ Tipo de Violência } & Física & $8,14(100,00)^{*}$ & $-5,48(0,00)$ \\
\hline & Psicológica & $0,31(24,30)$ & $-0,21(0,00)$ \\
\hline & Sexual & $-7,11(0,00)$ & $4,79(100,00)^{*}$ \\
\hline & Outras ${ }^{2}$ & $7,00(100,00)$ & $-4,71(0,00)$ \\
\hline & Física-Psicológica & $3,30(99,90)^{*}$ & $-2,22(0,00)$ \\
\hline & Física-Sexual & $-1,56(0,00)$ & $1,05(70,80)$ \\
\hline & Física-Outras & $5,39(100,00)^{*}$ & $-3,63(0,00)$ \\
\hline & Psicológica-Sexual & $-2,53(0,00)$ & $1,71(91,20)^{*}$ \\
\hline & Psicológica-Outras & $0,43(33,02)$ & $-0,29(0,00)$ \\
\hline & Física-Psicológica-Sexual & $-3,00(0,00)$ & $2,02(95,64)^{*}$ \\
\hline & Física-Psicológica-Outras & $2,01(95,57)^{*}$ & $-1,35(0,00)$ \\
\hline & Física-Sexual-Outras & $-0,77(0,00)$ & $0,52(39,75)$ \\
\hline & Psicológica-Sexual-Outras & $-0,90(0,00)$ & $0,60(45,43)$ \\
\hline \multirow{8}{*}{ Tipo de Relação } & Mãe & $6,70(100,00)^{*}$ & $-4,56(0,00)$ \\
\hline & Pai & $-2,07(0,00)$ & $1,41(84,11)^{*}$ \\
\hline & $\operatorname{Irmão(ã)}$ & $-0,12(0,00)$ & $0,08(6,26)$ \\
\hline & Padrasto & $-4,68(0,00)$ & $3,19(99,86)^{*}$ \\
\hline & Conhecidos(as) & $-0,21(0,00)$ & $0,14(11,35)$ \\
\hline & Desconhecido(a) & $-1,57(0,00)$ & $1,07(71,40)^{*}$ \\
\hline & Pai-Mãe & $3,27(99,89)^{*}$ & $-2,23(0,00)$ \\
\hline & Mãe-Padrasto & $0,38(29,28)$ & $-0,26(0,00)$ \\
\hline \multirow{3}{*}{ Sexo do Autor } & Masculino & $-3,76(0,00)$ & $2,53(98,87)^{*}$ \\
\hline & Feminino & $6,14(100,00)^{*}$ & $-4,14(0,00)$ \\
\hline & Ambos & $3,43(99,94) *$ & $-2,31(0,00)$ \\
\hline
\end{tabular}

*Probabilidades fortemente significativas, pois $\gamma \times 100 \geq 70 \%$.

$* *$ Probabilidades moderadamente significativas, pois $50 \% \leq \gamma \times 100 \leq 70 \%$.

1 Outros (Ambiente virtual; Barco; Conselho tutelar; Creche; Dentro do carro; Fazenda; Hospital; Igarapé; Igreja; Mata; Motel; Residência da babá; Residência da mãe; Residência de um parente (Tio(a), Irmão(ã), Avô(ó); Primo(a)); Residência do pai; Residência do(a) vizinho(a); Residência do(a) amigo(a); Sítio e etc.).

${ }^{2}$ Outras (Abandono; Patrimonial; Tortura; Trabalho infantil e etc.).

Fonte: Sistema de Informação de Agravos de Notificação (SINAN). Adaptado pelos autores.

\section{Discussão}

A partir dos resultados, foi possível observar que em Belém, capital do estado do Pará, foram registrados 2.341 casos de violência contra crianças na primeira infância, e na cidade de Ananindeua que faz parte da região metropolitana de Belém, apresentou 638 casos, sendo que juntas somaram 2.979 casos, o que representa mais da metade de casos registrados em todo o estado (Figura 1).

Todavia, esses dados devem ser analisados com cautela, pois capitais e regiões metropolitanas concentram maior quantidade e diversidade de instituições e equipamentos da rede de atendimento, o que é mais escasso nos demais municípios. Além disso, observa-se maior presença de equipamentos em Belém e Ananindeua, e menor presença nos municípios mais distantes da região metropolitana (Silva \& Hage, 2017). Um dos fatores, portanto, que pode justificar o elevado número de 
casos de violências ocorridos e registrados na capital do estado e na cidade de Ananindeua.

Em relação a análise das variáveis, os resultados demonstram que a grande maioria $(69,05 \%)$ das vítimas é do sexo feminino (Tabela 1). A quantidade expressiva de vítimas do sexo feminino pode ser explicada também por questões relacionadas a violência de gênero, que colocam as mulheres como objeto sexual e em posição de desigualdade, fazendo com que crianças e adolescentes estejam mais vulneráveis também nesse contexto, quando se considera a violência sexual (Duarte \& Arboleda, 1997; Oliveira, 2006).

A violência de gênero é resultado de uma assimetria de poder, que se traduz em relações de força e dominação, reproduzida às crianças que, no âmbito intrafamiliar, constituem o polo desfavorecido da relação de poder intergeracional (Fonseca et al, 2012).Esse tipo de violência ocorre desde a infância, onde adultos figuram como dominadores e as crianças como dominados, sendo que essa hierarquia começa no chefe da família e termina no mais frágil dos seus filhos, provavelmente filhas (Saffioti, 2004)

O Boletim Epistemológico, editado pela Secretaria de Vigilância em Saúde do Ministério da Saúde em 2018, apresentou dados semelhantes em estudo sobre a violência sexual contra crianças e adolescentes no Brasil nos anos de 2011 a 2017. O referido estudo mostrou que 43.034 (74,2\%) das vítimas de violência sexual eram do sexo feminino e $14.996(25,8 \%)$ do sexo masculino (Brasil, 2018).

Sobre o local de ocorrência da violência contra crianças e adolescentes constatou-se que 86,26\% dos registros apontam para a residência desses sujeitos (Tabela 1). Este resultado traz a reflexão sobre a idealização do espaço do lar como o local mais seguro e harmônico para a criança, na medida em que a violência pode ser praticada de forma silenciosa ao longo dos anos por familiares e conhecidos das vítimas (Marques et al., 2008; Pelisoli et al., 2010).

Resultado semelhante também é observado no Boletim Epistemológico do Ministério da Saúde de julho de 2020 em que apontou que a maior parte dos autores tinha vínculo familiar e amizade/conhecimento com as vítimas (Brasil, 2020a).

Em relação ao autor da violência, grande maioria $(77,70 \%)$ é do sexo masculino (Tabela 1). Resultado idêntico foi identificado em estudo realizado em 2015, sobre a predominância do sexo masculino entre os agressores. Isso levanta uma discussão sobre gênero e as diferenças entre os sexos que leva a desigualdade por meio da dominação e exploração entre pares, o que dificulta o desenvolvimento de um sistema de vigilância e de informações mais efetivas, na medida em que muitos casos de violência passam a ser revelados após a consolidação da exploração e dominação (Veloso, 2015).

Há uma tolerância social, tanto da vitimização de meninas quanto da perpetração por parte de meninos e de homens, o que torna as crianças, e especialmente as meninas, vulneráveis à violência que é muitas vezes vista como normal e que, ao lado da vergonha, do medo e da crença de que ninguém pode ajudar, resulta em baixos níveis de denúncia às autoridades. Além disso, as vítimas muitas vezes são consideradas culpadas pela violência que sofreram. Essa tolerância da sociedade em relação à violência em geral decorre do status inferior de mulheres e crianças em muitas sociedades, e de normas culturais relacionadas a gênero e masculinidade. (WHO, 2016).

Os resultados quanto a relação do autor da violência com a vítima, observa-se que conhecidos são predominantemente os autores da violência tanto quando se refere à vítima do sexo feminino quanto à vítima do sexo masculino (Tabela 1). A participação de amigos e conhecidos tem se destacado cada vez mais em estudos publicados acerca da violência, o que revela à facilidade na abordagem às vítimas, a confiança adquirida pelo agressor, que usa desta condição para se aproximar e assim desencadear o processo da violência. Sendo ainda que esta aproximação pode ser realizada de forma sedutora ou com o uso de força física (Veloso, 2015).

Importante destacar um estudo similar a este que foi desenvolvido com objetivo de apresentar o quadro de violência doméstica, sexual e outras violências perpetradas contra crianças (0-9 anos) no Brasil no ano de 2010. Entre os resultados, chama atenção a conclusão de que em bebês (crianças até um ano de idade), a negligência e a violência física são os tipos mais 
comuns de violência. Nesta faixa etária, o ambiente doméstico é o espaço privilegiado de ocorrência da violência, tendo a mãe como a principal agressora. A partir de 1 ano de idade, outras formas de violência ganham destaque, em especial a física, a sexual e a psicológica (Assis, 2012).

Outro estudo sobre violência em crianças no município de Ribeirão Preto, em São Paulo, região sudeste do Brasil, no período 2006-2008, analisou 498 notificações de violência contra crianças de zero a nove anos de idade e obteve os seguintes resultados: Predominaram vítimas do sexo feminino, na idade entre dois e cinco anos (mais de 60\%). A maioria dos agressores era do sexo masculino $(53,6 \%)$, destacando-se a figura paterna $(22,7 \%)$. Agressões físicas foram as mais praticadas e, para todos os tipos de agressões, o local de maior ocorrência foi a residência da família (Farias et al., 2016).

Do mesmo modo, em estudo realizado com a finalidade de analisar notificações de violências contra crianças de 0 a 9 anos, registradas pelos serviços públicos de saúde no Brasil, concluiu-se que a maior frequência das violências foi no ambiente doméstico, em meninas, sendo os pais os agressores mais frequentes. A violência se caracterizou pela repetição da ocorrência, sendo o uso de bebidas alcoólicas pelo agressor relatado em um quarto dos casos. A negligência foi o tipo mais notificado, seguida pela física, sexual e a psicológica. A negligência e a violência física têm maior chance de ocorrer em meninos, e a sexual e psicológica em meninas (Rates et al., 2015).

Segundo dados do Anuário Brasileiro de Segurança Pública de 2020, a maior parte das vítimas de estupro e estupro de vulnerável são do sexo feminino, representando cerca de 85,7\%. A comparação dos dados sobre a idade da vítima por sexo aponta para disparidades entre homens e mulheres (e meninos e meninas) na vitimização sexual, sendo que entre as vítimas do sexo masculino, os casos estão mais concentrados durante a infância, e entre as vítimas do sexo feminino a violência sexual acontece mais frequentemente durante a adolescência. Os dados mostram também que o auge da vitimização entre as vítimas do sexo masculino se dá aos 4 anos de idade, enquanto entre as vítimas do sexo feminino isto acontece aos 13 anos. Os estupros se concentram nas faixas etárias mais baixas, sendo que 38,2\% ocorrem dos 0 aos 9 anos, $43,5 \%$ entre 10 e 14 anos e $18,4 \%$ entre 15 e 19 anos (FBSP, 2020b).

\section{Considerações Finais}

Os resultados deste estudo demonstraram que um percentual importante de crianças sofreu violência na primeira infância e as consequências podem impactar todo seu ciclo de vida. Além disso, essas violências afetam a curto e a longo prazo a saúde pública e os custos econômicos comprometendo os investimentos em educação, saúde e bem-estar da criança, reduzindo suas potencialidades ao atingirem a idade adulta.

Apesar dos avanços mencionados em torno da questão das políticas de proteção e prevenção à violência contra crianças, o cenário brasileiro ainda é desfavorável. Por isso, o conhecimento das peculiaridades do desenvolvimento das crianças principalmente na fase da primeira infância requer um processo de conscientização e identificação mais rigoroso e proativo, porque essas crianças são fisicamente dependentes dos adultos e estão em situação peculiar de desenvolvimento.

Pela análise dos dados, infere-se que no estado do Pará a vitimização do sexo feminino supera em grande parte a do sexo masculino, crianças do sexo feminino na idade de 5 anos sofrem mais violência na primeira infância e crianças do sexo masculino são mais vitimadas na idade de 6 anos, a raça/cor preta/parda predominam tanto em relação às vítimas do sexo masculino quanto do sexo feminino. A violência ocorre predominantemente na residência das crianças. $\mathrm{O}$ tipo de violência que se destaca é a violência sexual, seguido da violência psicológica-sexual e da violência física-psicológica-sexual. O conhecido da vítima representa o maior agressor, seguido do pai em relação às vítimas do sexo feminino e da mãe em relação às vítimas do sexo masculino. $\mathrm{O}$ autor da violência é predominantemente do sexo masculino em relação a vítima do sexo feminino é predominante também em relação a vítima do sexo masculino.

Com a aplicação da análise correspondência, observou-se peculiaridades entre as quais destaca-se que crianças do 
sexo masculino estão associadas a vitimização em escolas e a outros locais, já crianças do sexo feminino estão associadas a vitimização em residência. Crianças do sexo masculino estão associadas às violências do tipo física e outros tipos de violência e, também, as combinações das violências física-psicológica; física-outras e física-psicológica-outras, enquanto que crianças do sexo feminino estão associadas à violência do tipo sexual e, também, as combinações das violências física-sexual; psicológica-sexual e física-psicológica-sexual. Crianças do sexo masculino estão associadas à vitimização cometida pela mãe e pai e mãe, já crianças do sexo feminino estão associadas à vitimização cometida pelo pai, pelo padrasto e por desconhecido. Crianças do sexo masculino estão associadas à vitimização cometida por autores do sexo feminino e de ambos os sexos, já crianças do sexo feminino estão associadas à vitimização cometida por autores do sexo masculino. Em síntese, a violência praticada contra meninos difere da violência praticada contra meninas, em relação às características do autor, da vítima e quanto as circunstâncias do fato.

De modo geral, percebe-se que a questão de gênero é o maior diferencial na violência na primeira infância, sendo que o tipo de violência contra crianças do sexo masculino e suas circunstâncias não apresenta semelhança significativa com relação a violência contra crianças do sexo feminino. Portanto, entre os resultados, pode-se identificar o ponto considerado de maior relevância nesta pesquisa que é a predominância da violência sexual associado ao fato da vítima ser do sexo feminino. Embora a subnotificação da violência seja elevada, em especial a violência sexual contra meninos.

Diante dos resultados, este estudo sugere o desenvolvimento de trabalhos futuros de análise específica sobre a caracterização da violência sexual contra crianças na primeira infância, considerando as peculiaridades de cada idade, para comparar com outras faixas etárias. Para tanto, destaca-se a necessidade de outras pesquisas que versam sobre as evidências encontradas neste estudo, bem como sobre as percepções de profissionais que atuam no recebimento e investigação de notificação envolvendo crianças e adolescentes para que se possa realizar uma leitura de todo o processo de notificação e assim contribuir de forma mais efetiva para o enfrentamento da violência contra esses sujeitos.

\section{Referências}

Adolescente e dá outras providências. http://www.planalto.gov.br/ccivil_03/leis/18069.htm

Assis, S. G. de., Avanci, J. Q., Pesce, R. P., Pires, T. de O., \& Gomes, D. L. (2012). Notificações de violência doméstica, sexual e outras violências contra crianças no Brasil. Ciência \& Saúde Coletiva, 17(9), 2305-2317. 10.1590/s1413-81232012000900012

Comitê Científico do Núcleo Ciência pela Infância - NCPI. (2014). Estudo nº 1. O Impacto do Desenvolvimento na Primeira Infância sobre a Aprendizagem: Fundação Maria Cecília Souto Vidigal. https://ncpi.org.br/wp-content/uploads/2018/07/O-IMPACTO-DO-DESENVOLVIMENTO-NA-PRIMEIRAINFaNCIA-SOBRE-A-APRENDIZAGEM.pdf

Constituição da República Federativa do Brasil de 1988. http://www.planalto.gov.br/ccivil_03/constituicao/constituicao.htm

Duarte, J. C., \& Arboleda, M. (1997). Malos Tratos Y Abuso Sexual Infantil: Causas, consecuencias e intervención. Madrid: Siglo XXI de España.

Egry, E. Y., Apostólico, M. R., Morais, T. C. P., \& Lisboa, C. C. R. (2017). Enfrentar a violência infantil na Atenção Básica: como os profissionais percebem? Revista Brasileira de Enfermagem, 70(1), 119-125. 10.1590/0034-7167-2016-0009

Farias, M. S., Souza, C. S., Carneseca, E. C., Passos, A. D. C., \& Vieira, E. M. (2016). Caracterização das notificações de violência em crianças no município de Ribeirão Preto, São Paulo, no período 2006-2008. Revista Epidemiologia e. Serviços de Saúde, 25 (4), 799-806. 10.5123/S1679-49742016000400013

Fávero, L. P. L., Belfiore, P. P., Silva, F. L. da., \& Chan, B. L. (2009). Análise dos Dados: modelagem multivariada para tomada de decisões: Elsever.

Felitti, V. J., Anda, R. F., Nordenberg, D., Williamson, D. F., Spitz, A. M., Edwards, V., Koss, M. P., \& Marks, J. S. (2019). Relationship of Childhood Abuse and Household Dysfunction to Many of the Leading Causes of Death in Adults: The Adverse Childhood Experiences (ACE) Study. American Journal of Preventive Medicine, 56(6), 774-786. 10.1016/j.amepre.2019.04.001

Fonseca, R. M. G. S., Egry, E. Y., Nóbrega, C. R., Apostólico, M. R., \& Oliveira, R. N. G. (2012). Reincidência da violência contra crianças no Município de Curitiba: um olhar de gênero. Acta Paul Enferm, 25 (6), 895-901. 10.1590/S0103-21002012000600011

Fórum Brasileiro de Segurança Pública (FBSP). (2020). 14 Anuário Brasileiro de Segurança Pública (ABSP). https://forumseguranca.org.br/wpcontent/uploads/2020/10/anuario-14-2020-v1-final.pdf.

Fredrickson, R. (2019). Trauma-Informed Care for Infant and Early Childhood Abuse. Journal of Aggression, Maltreatment \& Trauma, 28(4), 389-406. $10.1080 / 10926771.2019 .1601143$ 


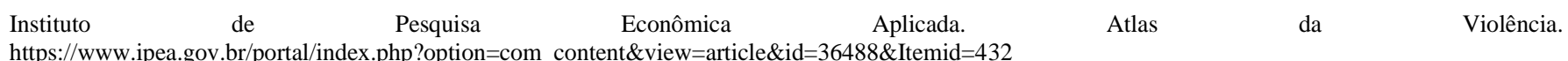

https://www.ipea.gov.br/portal/index.php?option=com_content\&view=article\&id=36488\&Itemid=432

Lei n. 13.010, de 26 de junho de 2014. Altera a Lei n. 8.069, de 13 de julho de 1990 (Estatuto da Criança e do Adolescente), para estabelecer o direito da criança e do adolescente de serem educados e cuidados sem o uso de castigos físicos ou de tratamento cruel ou degradante, e altera a Lei n. 9.394, de 20 de dezembro de 1996. http://www.planalto.gov.br/ccivil_03/_Ato2011-2014/2014/Lei/L13010.htm

Lei n. 13.960, de 19 de dezembro de 2019. Institui o Biênio da Primeira Infância do Brasil no período de 2020-2021. http://www.planalto.gov.br/ccivil_03/_ato2019-

2022/2019/lei/L13960.htm\#: :text=LEI\%20N\%C2\%BA\%2013.960\%2C\%20DE\%2019,per\%C3\%ADodo\%20de\%202020\%20a\%202021.

Lei n. 13.971, de 27 de dezembro de 2019. Institui o Plano Plurianual da União para o período de 2020 a 2023. http://www.planalto.gov.br/ccivil_03/_ato2019-2022/2019/lei/L13971.htm

Lei n. 8.069; de 13 de julho de 1990. Dispõe sobre o Estatuto da Criança e

Lei n. 9.394, de 20 de dezembro de 1996. Estabelece as diretrizes e bases da educação nacional. http://www.planalto.gov.br/ccivil_03/leis/19394.htm

Lei $\mathrm{n}^{\circ}$ 13.257, de 08 de março de 2016. Dispõe sobre as políticas públicas para a primeira infância. http://www.planalto.gov.br/ccivil_03/_ato20152018/2016/lei/113257.htm

Marconi, M. A., \& Lakatos, E. M. (2010). Fundamentos de metodologia científica: Atlas.

Marques, H. M. V., Amparo, D. M., \& Faleiros, V. P. (2008). O vínculo Transgeracional e o Teste de Rorschach de um abusador sexual. In: Penso M, Costa L, organizadores. A transmissão geracional em diferentes contextos: da pesquisa à intervenção: Summus.

Minayo, M. C. de S. (2001). Violência contra crianças e adolescentes: questão social, questão de saúde. Revista Brasileira de Saúde Materno Infantil, 1 (2), 91-102. 10.1590/S1519-38292001000200002.

Ministério da Mulher, da Família e dos Direitos Humanos (MDH). Secretaria de Direitos Humanos. Conselho Nacional dos Direitos da Criança e do Adolescente (Conanda). Plano nacional de enfrentamento a violência sexual contra crianças e adolescentes: MDH. https://www.gov.br/mdh/pt-br/centrais-deconteudo/crianca-e-adolescente/plano-nacional-de-enfrentamento-da-violencia-sexual-contra-criancas-e-adolescentes.pdf/view

Ministério da Mulher, da Família e dos Direitos Humanos (MMFDH). Disque Direitos Humanos. Relatório 2019: MMFDH. https://www.gov.br/mdh/ptbr/assuntos/noticias/2020-2/junho/balanco-anual-disque-100-atendeu-2-7-milhoes-de-ligacoes-em-2019/copy_of_Relatorio_Disque_100_final.pdf

Ministério da Saúde (MS). Secretaria de Atenção à Saúde. Departamento de Ações Programáticas Estratégicas. Linha de cuidado para a atenção integral à saúde de crianças, adolescentes e suas famílias em situação de violências: orientação para gestores e profissionais de saúde: MS. https://bvsms.saude.gov.br/bvs/publicacoes/linha_cuidado_criancas_familias_violencias.pdf

Ministério da Saúde (MS). Secretaria de Vigilância em Saúde. Boletim Epidemiológico, jun. 2018, vol. 49, n. 27: MS. https://portalarquivos2.saude.gov.br/images/pdf/2018/junho/25/2018-024.pdf

Ministério da Saúde (MS). Secretaria de Vigilância em Saúde. Boletim Epidemiológico, jul. 2020, 51(28): MS. https://antigo.saude.gov.br/images/pdf/2020/July/14/Boletim-epidemiologico-SVS-28-v2.pdf

Nunes, A. J., \& Sales, M. C. V. (2016). Violência contra crianças no cenário brasileiro. Ciência \& Saúde Coletiva, 21(3), 871-880. 10.1590/141381232015213.08182014

Oliveira, V. L. A. (2006). A violência doméstica contra crianças e adolescentes no município de Curitiba [Dissertação]: Programa de Pós-Graduação em Saúde Pública. Universidade de São Paulo (USP).

Pelisoli, C., Pires, J. P. M., Almeida, M. E., \& Dell'Aglio, D. D. (2010). Violência sexual contra crianças e adolescentes: dados de um serviço de referência. Temas em Psicologia, 18 (1), 85-97. http://pepsic.bvsalud.org/pdf/tp/v18n1/v18n1a08.pdf

Pereira, A. S., Shitsuka, D. M., Parreira, F. J., \& Shitsuka, R. (2018). Metodologia da pesquisa científica. [e-book]. Santa Maria. Ed. UAB/NTE/UFSM. https://repositorio.ufsm.br/bitstream/handle/1/15824/Lic_Computacao_Metodologia-Pesquisa-Cientifica.pdf?sequence=1

Porto, P. R. F. (2006). Anotações preliminares à Lei 11.340/2006 e sua repercussão em face dos Juizados Especiais Criminais: Livraria do Advogado.

Rates, S. M. M., Melo, E. M., Mascarenhas, M. D. M., \& Malta, D. C. (2015). Violência infantil: uma análise das notificações compulsórias, Brasil 2011. Ciência \& Saúde Coletiva, 20 (3), 655-665.

Saffioti, H. I. B. (2004). Gênero, patriarcado, violência: Fundação Perseu Abramo.

Sanchez, R. N., \& Minayo, M. C. S. (2006). Violência contra Crianças e Adolescentes: Questão Histórica, Social e de Saúde. In: Lima C, organizador. Violência faz mal à saúde: MS, p. 29-38.

Sekkel, M. C. (2009). O cuidado na educação contra a violência na primeira infância. Rev. Temas em Psicologia, 17 (2), 371-376. http://pepsic.bvsalud.org/pdf/tp/v17n2/v17n2a09.pdf

Silva, L. I., \& Hage, S. (2017). Violência e Violência Sexual contra Crianças e Adolescentes: Desafios para a Atuação da Rede de Proteção aos Direitos Humanos na Amazônia. In: Oliveira A. C. (Org.). Violência Sexual contra Crianças e adolescentes. Cenários Amazônicos, Rede de Proteção e Responsabilidade Empresarial: Lumen Juris. 
Research, Society and Development, v. 10, n. 1, e33510111839, 2021 (CC BY 4.0) | ISSN 2525-3409 | DOI: http://dx.doi.org/10.33448/rsd-v10i1.11839

Veloso, M. M. X. (2015). Maus-tratos contra crianças e adolescentes: limites e possibilidades de atuação de profissionais de saúde [Tese]. Belém-PA: Programa de Pós-Graduação em Teoria e Pesquisa do Comportamento. Universidade Federal do Pará (UFPA).

Veloso, M. M. X., Magalhães, C. M. C., Dell'Aglio, D. D., Cabral, I. R., \& Gomes, M. M. (2013). Notificação da violência como estratégia de vigilância em saúde: perfil de uma metrópole do Brasil. Ciência \& Saúde Coletiva, 18(5), 1263-1272. 10.1590/s1413-81232013000500011

Walker, S. P., Wachs, T. D., Grantham-McGregor, S., Black, M. M., Nelson, C. A., Huffman, S. L., Baker-Henningham, L., Chang, S. M., Hamadani, J. D., Lozoff, B., Gardner, J. M. M., Powell, C. A., Rahman, A., \& Richter, R. (2011). Inequality in early childhood: risk and protective factors for early child development. The Lancet, 378(9799), 1325-1338. 10.1016/s0140-6736(11)60555-2

Word Health Organization (WHO). (2002). World report on violence and health. Geneva.

Word Health Organization (WHO). (2016). INSPIRE: seven strategies for ending violence against children. Tradução em português: B\&C Textos. São Paulo: Núcleo de Estudos da Violência (NEV) da Universidade de São Paulo (USP). 